\title{
Reviewer Acknowledgements for Journal of Educational and Developmental Psychology, Vol. 10, No. 2
}

Journal of Educational and Developmental Psychology wishes to acknowledge the following individuals for their assistance with peer review of manuscripts for this issue. Their help and contributions in maintaining the quality of the journal are greatly appreciated.

Journal of Educational and Developmental Psychology is recruiting reviewers for the journal. If you are interested in becoming a reviewer, we welcome you to join us. Please e-mail the completed application form to jedp@ccsenet.org.

\section{Reviewers for Volume 10, Number 2}

Anjolii Diaz, Ball State University, United States of America

Anne Scott, Australian Catholic University, Australia

Belgin Aydin, Anadolu University, Turkey

Debra Burnett, Kansas State University, United States of America

Dharma Jairam, Morningside College, United States of America

Elizabeth Fraser Selkirk Hannah, University of Dundee, United Kingdom

Heejung Chun, Pukyong National University, Republic of Korea

Joaquin Linne, University of Buenos Aires/CONICET/University of Lanús, Argentina

Julie Ann Hadwin, University of Southampton, United Kingdom

Maria L. Reid, Florida International University, United States of America

Nicole Sankofa, University of North Texas, United States of America

Pat Moodley, Mpumalanga Department of Education, South Africa

Rita Anne Hagevik, The University of North Carolina, United States of America

Seungsoo Yeo, Inje University, Republic of Korea

Yagnamurthy Sreekanth, National Council of Educational Research and Training, India

Yu-Ri Kim, Ewha W. University, Republic of Korea 